\title{
Marker-Based Augmented Reality for Exhibition in Higher Education
}

\author{
Vidya Kharishma \\ Faculty of Creative Industry and Telematics, Trilogi University, Indonesia \\ Vidya.kharishma@trilogi.ac.id
}

\begin{abstract}
Nowadays, popularity in using AR (augmented reality) for artworks has increased. The technology offered by AR capable of making the audience becomes more interactive to apappreciate artworks. Responded to this popularity, this research analyzes the uses of marker-based AR for exhibition on art and design in Higher Education using visitor mobile devices. It aims to find an advantage and limitation on using marker-based AR technology for exhibition in higher education based initial theory and case study. The method used in this research is descriptive qualitative. The study conducted at the Aralana Exhibition, Trilogi University, as a case study of student and lecturer exhibitions in Higher Education. The finding of the research confirms a positive influence on the student as a visitor. AR technology stimulates the student experience to appreciate art and design by interactive with their mobile devices and motivate them to learn the technology. However, there is a limitation and challenge in art as an AR marker, requirements on exhibition guide, and availability of internet connection. With this finding, it is encouraged for artists and designers to collaborate with across disciplines so they can contribute to exploring the potential of using AR for artworks.
\end{abstract}

Keywords: augmented reality, marker-based AR, exhibition, art, artworks

\section{INTRODUCTION}

In recent years a trend has developed regarding AR (augmented reality) due to the rapid development of digital technology. The fact is now AR has been widely used in all fields. Many research explains how AR has penetrated many fields, including fields in medicine, military, manufacturing, visualization, entertainment and games, robotics, education, marketing and advertising, commerce, road planning and navigation, tourism, geospatial, urban planning and civil engineering.[1]-[3]

$\mathrm{AR}$ is different from virtual reality (VR), which uses computer technology to create an artificial or simulated environment. Ronald Azuma proposed the most widely accepted definition of AR in his 1997 survey paper. According to Azuma, AR must have the following three characteristics; (1) combine real and virtual, (2) interactive in real-time, (3) registered in 3D.[4] To differentiated between AR and VR can be seen in a recent study by Flavian, IbanezSanchez, and Orus. They adjust the Reality-Virtuality Continuum proposed by Milgram and Kashino (1994) by differentiating the independent dimension of "Pure Mixed Reality" (PMR) as shown in Figure 1. [5] 


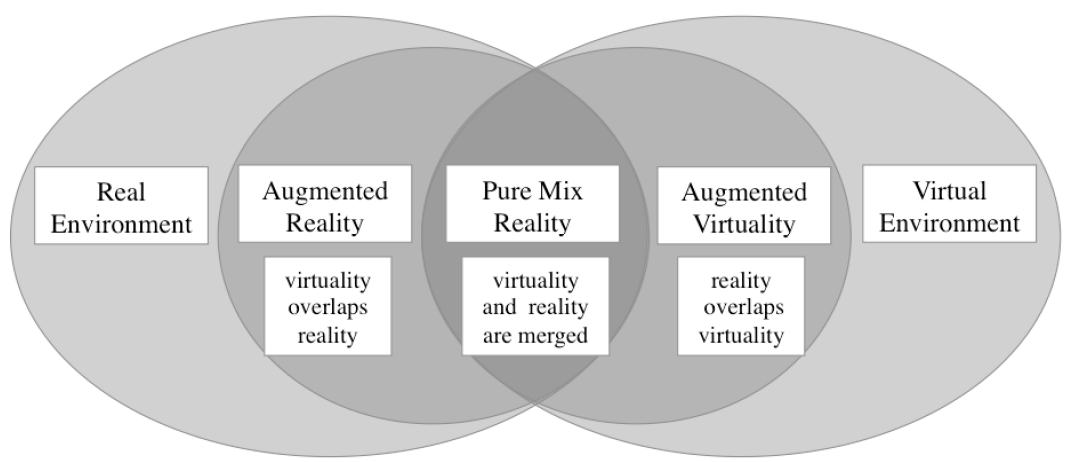

Fig. 1. Proposed reality-virtuality continuum by Flavian, Ibanez-Sanchez, and Orus.

AR system consists of three simple steps: Recognition, Tracking, and Mix. AR application recognizes any image, object, face, body, or space used as a marker. During tracking real-time localization in the space of the image, object face, a body or space is performed, and finally, media in the form of video, animation, or 3D superimposed over the marker. [6] There are two types of AR, which are marker-based, which uses cameras and visual cues, and marker less, which use positional data such as a mobile's GPS and compass .[7]

One of the trends in AR marker based is using it for in art and design exhibitions. The technology offered by AR capable of making the audience get an immersive experience. Hence, it changes the passive role of a visitor to become more active in terms of appreciating the artworks. Based on research by Marques, AR was shown to increase visitor interest and engagement with the content on display on exhibition and has a positive influence over visitors' satisfaction level.[8]

The advantages of using augmented reality for the exhibition are great opportunities for art and design students to learn how to open their creative minds with a different alternative using the technology. Involving students in the creation of marker-based AR projects is likely to serve to engage students more in the learning process. Results of studies by Bower, Howe, McCredie, Robinson, and Grover (2014) and Slussareff and Boháčková (2016) confirm the positive learning outcomes of student-generated AR. Students can be involved in both creating markers, by capturing images on their mobile devices, and in helping to create the augmentation, which can range from text annotations to video animations. [9] On another hand, there are several challenges and limitations when using AR for an exhibition based on some research. [10], [11] Many this research is from fields of informatics technology, not how AR studied from art and design views. Thus, this study will research more about the advantage and limitations of using AR-based markers for exhibitions in higher education in art and design point of view.

\section{METHOD}

This research uses descriptive qualitative research methods. The study conducted at the Aralana Exhibition, Trilogi University, as a case study of student and lecturer exhibitions in Higher Education. Before conducting the exhibition, the researcher conducted a trial and error to design marker-based AR artworks. This trial and error aim to know limitations and on using artworks for marker-based AR. After the exhibition over, a questionnaire conducted in the 
Trilogi University exhibition, which aims to know student's reactions, excitement, and motivation to learn AR technology.

AR Systems uses physical-world symbols as a reference point o overlaid by computer graphics. The camera in mobile devices continuously snapshots the target object and processes the image to estimate the position, orientation, and movement of the visualization display concerning the target object.[6] In this research, a two dimensional printed marker is placed in the exhibition. AR marker usually features a square frame with a black pattern on a white background color. Nevertheless, in this research, the marker uses an author and student artworks for a marker for AR. The process of how visitor can see an AR artwork illustrated in Figure 2. The visitor track the artworks using a camera tool in AR application installed on their mobile device. The application then interprets the artworks as a marker to overlay an onscreen animation that downloads from the application website. This download animation will looks as if it were directly on top of the marker in the physical world.

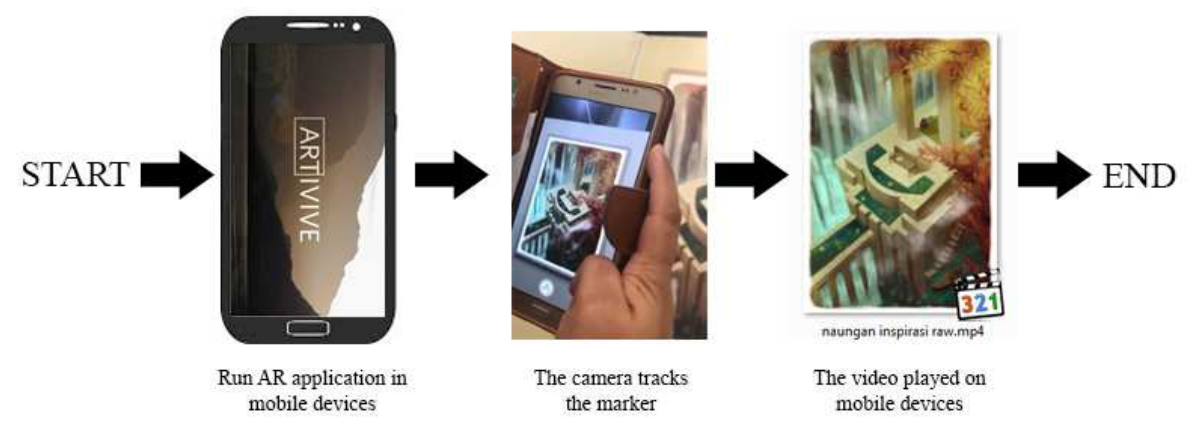

Fig. 2. Marker-based AR system

\section{RESULT AND DISCUSSION}

In this trial, the illustration and the animation were made using graphic design software, namely Adobe Photoshop. Then, the artworks converted into AR artworks by AR application. This research using Artivive, an AR application, because it is an easy application to use for artists and designers who do not know to program augmented reality from scratch. Furthermore, it will also be suitable for teaching art and design students who prioritize more on the artwork design rather than the technical aspect of augmented reality.

The finished AR artwork then displays at the Aralana exhibition. At this exhibition, to distinguish AR artworks from ordinary artworks, information put on display beside the AR artworks for a visitor to read. Also, there is an exhibition guide who informs visitors how augmented reality artwork works. They have installed an AR application on their mobile device to see the artworks.

Data collection is conducted directly by field observation during the exhibition and indirectly by watching AR statistics on the Artivive website. Based on these statistics, 32 mobile devices user ( 28 android users and 4 IOS users) has accessed the augmented reality artwork displayed at the Aralana exhibition, and the artworks have been viewed 295 times during the exhibition within three days. After the exhibition is over, a distribution questionnaire conducted to 72 students majoring in product design or visual communication design to analyze student's reactions, interests, and motivations to appreciates and learning AR 
artworks. Result in analyzing the data collection; there are several findings regarding the advantages and limitations of the use of AR in student exhibitions.

\subsection{Art Limitation as Augmented Reality Marker}

After several trials in making AR artworks using the Artivive, several problems arose, which indicates a limitation on how artworks can be uses for AR marker. The first time artworks $\mathrm{K} 1$ and $\mathrm{K} 2$ upload on the website, both artworks were failed to be used as markers because they are hard to be recognized by system. It is sufficient after several adjustments on the contrast level of artworks. Even after adjusting, the recognition speed level in the artwork is only one star. While in artwork K3 and K4, it immediately gets recognition speeds level of 3 and 4 stars. This comparison can be seen in Table 1.

Table 1. Comparison study of AR marker recognition speed on the author's artworks

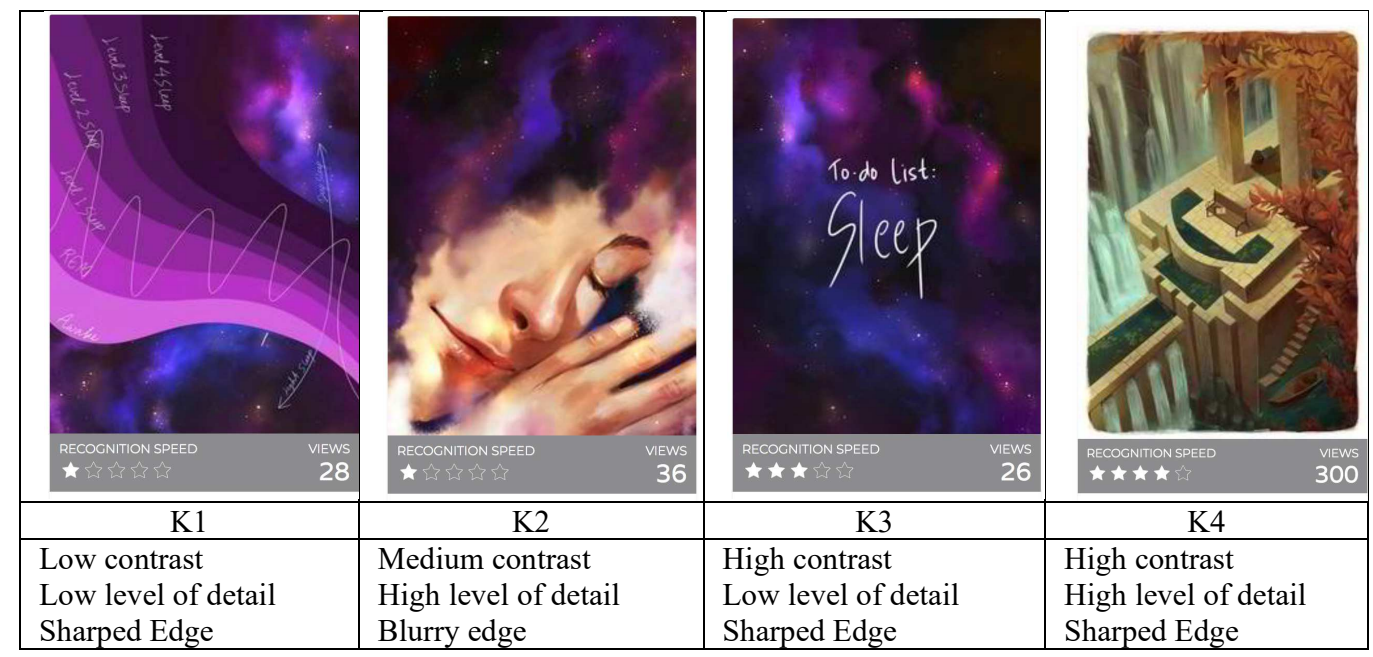

To find more justified result, the author converted eight artworks of students with different illustration styles to augmented reality artworks marker. The result of students artworks comparison as shown in Table $\mathbf{2}$ is more or less the same with the first comparison. There is a clear connection between contrast and recognition speed on the AR marker. Four or five-level of star recognition found in Artworks with high contrast values and colors. Meanwhile, the level of detail on artworks surprisingly has a little influence on recognition speed, but how sharped the drawing can increase the recognition speed. This limitation is the same as previous research, in which the system is only able to detect an object that has a rich surface feature (point or edge). [11] Poor lighting in the exhibition might decrease the capability of object recognition. Consequently, all of this will limit the style of artworks with low contrast in color and value to be an AR marker. 
Table 2. Comparison study of AR marker recognition speed on students artworks

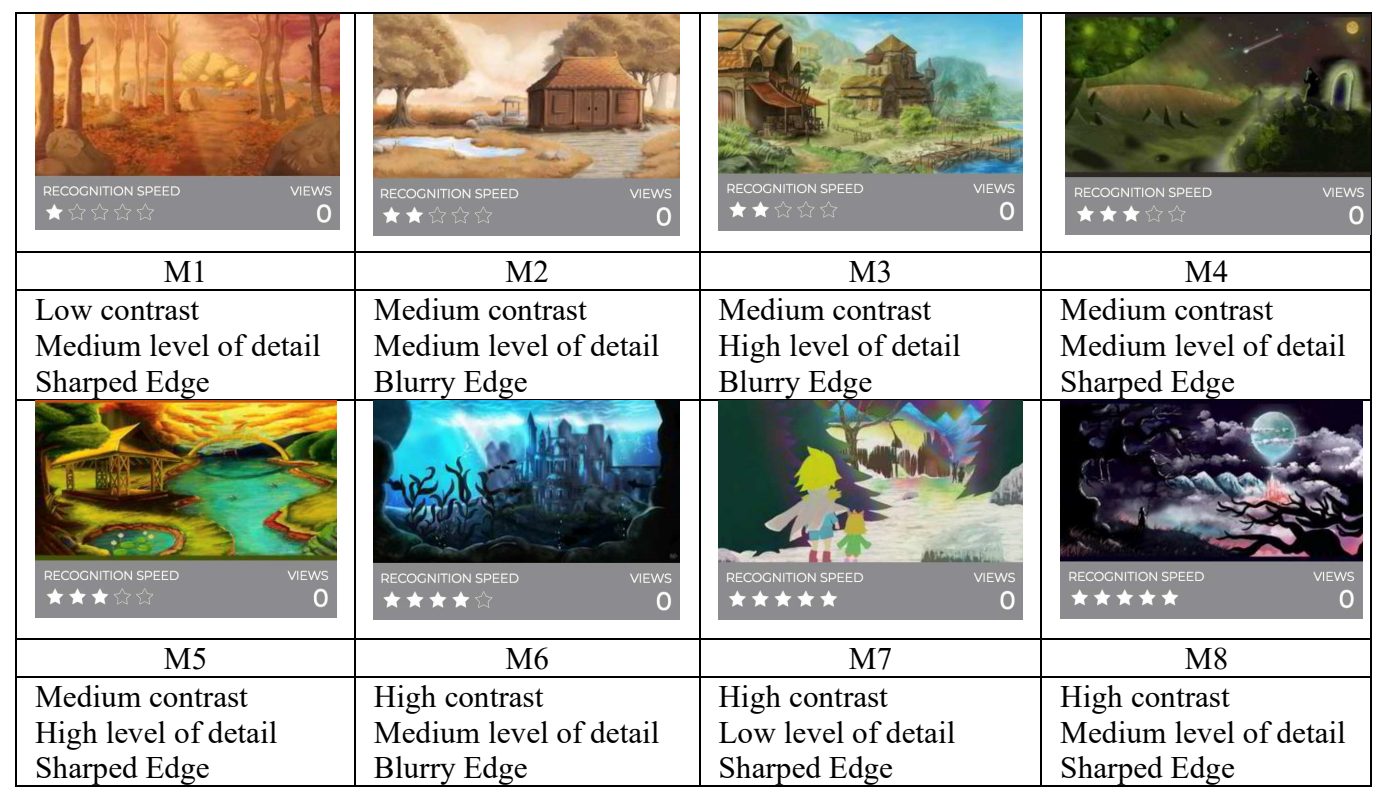

\subsection{Student Positive Reaction to Appreciate and Learn AR Technology Application on Artworks}

Uses of augmented reality artworks as a new media for student exhibitions are responded positively by students. Based on the questionnaire distributed to students, 63 of 72 respondents $(87 \%)$ had seen the video/animation in AR artwork displayed at the Aralana exhibition, and only $14 \%$ responded that had not seen it. Also, the majority of students, $97 \%$ of the respondents were interested in using AR artworks at student exhibitions after appreciating AR artworks in Aralana Exhibition. The novelty of augmented reality media can inspire students' excitement in appreciating art and design in the exhibition. AR artworks stimulate their interest in how the augmented reality artworks revealed the hidden virtual animation or artworks on the displayed artworks in reality.

In addition to the positive results in a questionnaire about student interest in AR artworks, based on a questionnaire, $97 \%$ of students were also motivated to make AR works. The results of the questionnaire show that augmented reality artworks as a new media motivated students to learn it. This discovery opens new alternatives for students to appreciate artworks and make experimental AR artworks in the student exhibition.

\subsection{The Necessary of Exhibition Guide in AR Exhibition and Installed AR Application in Visitor Mobile Devices}

The absence of AR applications on student mobile devices does not prevent students from appreciating art and design. Among the 63 respondents who have seen the animation in augmented reality artwork, only $25 \%$ (16 respondents) have the application on their own mobile devices. The highest number of $44 \%$ ( 28 students) saw the animation on augmented 
reality artwork by using the application installed on the exhibition guide and the rest of the respondents using the application installed on a friend's mobile device. Although many people do not have augmented reality applications to access augmented reality artworks, they still try to find people who have augmented reality applications because of their curiosity and interest in enjoying augmented reality artworks. Also, at the next question about the willfulness students to install the augmented reality application on their mobile devices, $94 \%$ of students were positive about does not mind to install it. This result means the majority of students will install the augmented reality application to enjoy the artworks if instructed.

Based on the questionnaire above also shows the importance of the exhibition guide to inform a visitor on how to access augmented reality artworks. They must have the application on their mobile devices to see the artworks. As a comparison, the author compared the statistics of augmented reality artworks between artworks at the Aralana Exhibition and artworks in the Bandung Connex Exhibition. The result is the artworks at the Aralana Exhibition, which was accompanied by an exhibition guide and had the augmented reality application installed on their mobile devices has more view rates than the artworks at Bandung Connext Exhibition, which has none of those two and just use label and informative panels. The view has a significant difference where artworks at the Aralana exhibition, which runs for three days, get 295 views while artworks at Bandung Conext exhibition that runs for a week only gets 37 views. The information panel beside the artworks alone evidently not enough material to guide visitors to enjoy augmented reality artworks. Exhibition guide might be needed for requirements because augmented reality applications are not widespread and are still rarely installed on mobile devices of the general public.

Provision of mobile device to see artworks in an exhibition or museum as in previous research is not enough solution for AR exhibition to run smoothly. [12] Based on similar research with the similar problem on mobile device requirement during the exhibition, there is some issue when an exhibition guide can not serve all visitors who want to borrow or use mobile devices provided to see an AR artwork. [13] Thus, this research suggests that there should be a media promotion as prior information for the visitors so they have a time to download and install the required applications before they come to the exhibition [14].

\subsection{Efficiency in The Use of AR technology for Video or Animation Exhibition}

In each semester at Trilogi University, there is always an exhibition of student artworks besides. Usually, students' videos/animations displayed at a specific time in a closed room with television or projector facilities. Rarely, these works can display in campus public spaces with more flexible time due to limited tools to display all the video/animation and for security reasons.

AR technology that utilizes cameras and applications on visitor's mobile devices to display animations and videos can be a solution to these problems. Students only need to display AR markers for their videos/animations in an exhibition so the visitor can track the marker using AR applications on their mobile devices to see the video/animation. However, one important thing to note is the availability of internet quota. As it is known, the longer the duration of a student's video or animation work, the longer the visitor will download the artworks. Based on statistics, visitors see animation/videos on augmented reality artworks in 2-4 times. Therefore, choosing the duration to display videos/animations is vital for the comfort of visitors to enjoy animation/videos displayed on AR. 


\section{CONCLUSION}

With the popularity of AR in society and technological developments, AR has the potential as an alternative in presenting student work at exhibitions. The limitations and advantages of AR explained in this study very influenced not just by the technology, but human knowledge of those technologies itself. However, these limitations and advantages are more likely to change in the future, according to developments in digital technology. Considering this, artists and designers encouraged to contribute to exploring the potential of using augmented reality for art and design together with people from across disciplines, especially from informatics technologies.

\section{REFERENCES}

[1] M. Mekni and A. Lemieux, "Augmented reality: Applications, challenges and future trends," Appl. Comput. Sci., pp. 205-214, 2014.

[2] A. O. Alkhamisi, S. Arabia, and M. M. Monowar, "Rise of augmented reality: current and future application areas," Int. J. Internet Distrib. Syst., vol. 1, no. 04, p. 25, 2013.

[3] I. Naaz and A. Sharma, "Rise of augmented reality: applications, challenges, and future trends," Int. J. Adv. Res. Ideas Innov. Technol., vol. 04, no. 06, pp. 725-731, 2018.

[4] D. Schmalstieg and T. Hollerer, Augmented Reality: Principles and Practice. USA: AddisonWesley Professional, 2016.

[5] C. Flavián, S. Ibáñez-Sánchez, and C. Orús, "The impact of virtual, augmented and mixed reality technologies on the customer experience," J. Bus. Res., vol. 100, pp. 547-560, 2019.

[6] D. Amin and S. Govilkar, "Comparative study of augmented reality SDKs," Int. J. Comput. Sci. Appl., vol. 5, no. 1, pp. 11-26, 2015.

[7] R. S. Patkar, S. P. Singh, and S. V Birje, "Marker based augmented reality using Android os," Int. J. Adv. Res. Comput. Sci. Softw. Eng., vol. 3, no. 5, 2013.

[8] D. C. V. Marques, "The Visitor Experience Using Augmented Reality on Mobile Devices in Museum Exhibitions (PhD Thesis)," University of Porto, 2017.

[9] R. Godwin-Jones, "Emerging Technologies Augmented Reality and Language Learning: From annotated vocabulary to place-based mobile games," Lang. Learn. Technol., vol. 20, no. 3, pp. 9-19, 2016.

[10] C. Ciurea, C. Coseriu, and C. Tudorache, "Implementing mobile applications for virtual exhibitions using augmented reality," J. Mobile, Embed. Distrib. Syst., vol. 6, no. 3, pp. 96-100, 2014

[11] A. Selvam, T. T.-V. Yap, H. Ng, H.-L. Tong, and C.-C. Ho, "Augmented reality for information retrieval aimed at museum exhibitions using smartphones," J. Eng. Appl. Sci., vol. 100, no. 3, pp. 635-639, 2016.

[12] R. Pierdicca, E. Frontoni, P. Zingaretti, M. Sturari, P. Clini, and R. Quattrini, "Advanced interaction with paintings by augmented reality and high resolution visualization: a real case exhibition," in International Conference on Augmented and Virtual Reality, 2015, pp. 38-50.

[13] J. E. Mat-Jizat, J. Osman, R. Yahaya, and N. Samsudin, "The use of augmented reality (AR) among tertiary level students: perception and experience," Aust. J. Sustain. Bus. Soc., vol. 2, no. $1,2016$.

[14] K. Saddhono, E. Satria, A. Erwinsyah, and D. Abdullah, "Designing SwiSH Max Learning Software Based of Multimedia," in Journal of Physics: Conference Series, 2019. 